\title{
UMA FACA DE DOIS GUMES: MOBILIZAÇÃO MILITAR E CAPACIDADE ADMINISTRATIVA DURANTE A GUERRA CIVIL AMERICANA
}

\author{
Arnaldo Lucas Pires Júnior ${ }^{1}$
}

\section{A Double-Edged Sword: $O$ papel da Escravidão no esforço de guerra confederado}

Our new government is founded upon exactly [this] idea; its foundations are laid, its corner-stone rests, upon the great truth that the negro is not equal to the white man; that slavery subordination to the superior race, is his natural and normal condition. This, our new government, is the first, in the history of the world, based upon this great physical, philosophical, and moral truth.

Alexander Stephens ${ }^{2}$

A experiência de uma República constituída diretamente sobre o argumento da defesa da escravidão enquanto regime de trabalho é singular. Mais único ainda é o fato de que o Estado surgido deste processo tenha de desenvolver seu estágio inicial de state-building em uma guerra de amplas proporções, como a Guerra Civil Americana. Não nos enganemos, o manejo de um conflito militar dentro das estruturas escravocratas não é inovador per si, já que diferentes Estados encontraram diversas soluções para coadunar esforço militar e manutenção de conflitos com a instituição da escravidão moderna. Contudo, nenhum deles foi tão imerso em uma guerra que duraria quatro longos anos, que custaria mais de 800.000 almas e - esse ponto é fundamental -, na qual a própria continuidade das estruturas governamentais $e$ da instituição escravocrata estavam em jogo.

Dessa forma, percebe-se como a escravidão, por constituir parte fundamental dos elementos justificativos para a consolidação do Estado Confederado, atingia diretamente suas capacidades extrativas e logísticas durante o conflito. É sobre este binômio - estrutura escravocrata e esforço militar - que procurarei me debruçar nas

${ }^{1}$ Doutorando pelo Programa de Pós-graduação em História Social da Universidade Federal do Rio de Janeiro (PPGHIS-UFRJ). E-mail: <saadlucas@gmail.com>.

2 "Nosso novo governo é fundamentado exatamente nessa ideia; seus alicerces estão dados, sua pedra angular repousa sobre a grande verdade de que o negro não é igual ao homem branco; que a subordinação da escravidão à raça superior é sua condição natural e normal. Este, nosso novo governo, é o primeiro na história do mundo baseado nesta grande verdade física, filosófica e moral" (Tradução nossa) The Cornerstone Speech, Savannah, Georgia, 21 de março de 1861. Disponível em: https://www.ucs.louisiana.edu/ ras2777/amgov/stephens.html 
próximas páginas, tentando compreender de que forma essa relação se dava $e$, principalmente, até que ponto ela se constituiu em passivo para a estrutura militar confederada diante do esforço de guerra.

Defenderei, ao longo das próximas páginas, que a relação entre escravidão $e$ mobilização militar na confederação deve ser entendida como um paradoxo. A razão desse paradoxo é muito clara, ao mesmo tempo em que foi a defesa do regime escravocrata - em oposição à ideologia do trabalho livre Yankee - que arregimentou forças para a instituição e consolidação do Estado confederado, foi ela também que apontou limites para ação do Governo Central, ditou as formas com as quais se daria a relação entre autoridades centrais e locais e, enfim, acabou por se transformar em um passivo extremamente alto na logística militar, diante da política de contrabando de guerra proposta pela União. A manutenção do regime escravocrata foi forte o suficiente para unir diferentes estados sulistas em torno de uma bandeira comum, porém, no mesmo movimento, agravou a situação de inferioridade em que a Confederação se encontrava, principalmente quando consideradas as questóes demográfica e econômica. A causa pela qual os confederados bradavam suas espadas acabou se mostrando uma "faca de dois gumes (a double-edged sword)".

Poucas causas poderiam mobilizar tão diretamente o Sul quanto a questão da escravidão, durante as décadas que antecederam a Guerra Civil. A maioria das análises em relação às tensões que se estendiam desde a vitória na Guerra contra o México, passando pelos compromissos de 1820 e 1850 e culminando com as tensões geradas pela Fugitive Slave Law, nos mostram de maneira clara como o tema do trabalho escravo e a oposição exercida por parte dos defensores da ideologia do trabalho livre, cada vez mais organizada no cenário político, se constituíam como dois pilares centrais de discussão na política interna americana. ${ }^{3}$ As tensões expressas no simbólico discurso "The irrepressible Conflict", do Senador republicano Willian H. Seward, são resultado de um conjunto de tensões que, se haviam sido contornadas à duras penas dentro do Segundo Sistema Partidário, pareciam fadadas à destruição após o surgimento do Partido Republicano.

A constatação da escravidão como leitmotiv da secessão parece hoje um ponto passivo entre historiadores. A discussão dos argumentos em favor da tese da defesa do direito dos estados nos parece batida e o esforço de refutá-la, aqui, seria desnecessário e inócuo, tendo em vista nossos objetivos. Contudo, é importante perceber que, mais que uma simples caracterização de intenções, apontar a escravidão como o motivo central para a secessão é a ressaltar um paradoxo estrutural contido na própria gênese do Estado Confederado. A Confederação baseava-se em toda uma retórica republicana - adotou constituição extremamente semelhante à de 1787 e recorria com frequência à memória dos pais fundadores -, mas reafirmava a diferença racial e pautava-se em uma noção de diferença natural entre os homens.

Essa noção de cidadania contida pelas fronteiras raciais trazia o primeiro grande desafio ao Estado confederado, o de mobilizar todo um conjunto de pessoas em torno

\footnotetext{
${ }^{3}$ Para uma análise mais detalhada das tensões posteriores à Guerra contra o México e a forma com a qual a vitória neste conflito acabou acirrando as cisões nas estruturas políticas americanas ver: MCPHERSON, James M. Battle Cry of Freedon: The Civil War era. New York: Balantine Books, 1989, p. 47-77.
} 
de uma instituição que beneficiava diretamente apenas uma minoria da população branca. Em nenhum dos estados do Sul o número de famílias possuidoras de escravos era maior do que o de brancos livres, como pode ser visto na tabela 1 . O que, a princípio, parece ser um contrassenso, explica-se quando analisamos não somente o papel de importância política que estes senhores de escravos possuíam no contexto político local, mas também quando abordamos a questão pelo viés da supremacia branca e da ameaça, ao menos assim compreendida pelos brancos sulistas não possuidores de escravos, aos status sociais de brancos pobres.

\section{TABELA 1 - PROPORÇÃO DE POSSUIDORES DE ESCRAVOS POR ESTADO}

\begin{tabular}{|c|c|c|c|}
\hline Estado & $\begin{array}{c}\text { Famílias } \\
\text { possuidoras de } \\
\text { escravos }\end{array}$ & $\begin{array}{c}\text { Famílias } \\
\text { brancas }\end{array}$ & $\begin{array}{c}\text { Porcentagem } \\
\text { (\%) }\end{array}$ \\
\hline Mississippi & 30943 & 63015 & 49 \\
\hline Carolina do Sul & 26701 & 58642 & 46 \\
\hline Georgia & 41084 & 109919 & 37 \\
\hline Alabama & 33730 & 96603 & 35 \\
\hline Florida & 5152 & 15090 & 34 \\
\hline Louisiana & 22033 & 74725 & 29 \\
\hline Texas & 21878 & 76781 & 28 \\
\hline Carolina do Norte & 34658 & 125090 & 28 \\
\hline Virginia & 52128 & 201523 & 26 \\
\hline Tennessee & 36844 & 149335 & 25 \\
\hline Kentucky & 38645 & 166321 & 23 \\
\hline Arkansas & 11481 & 57244 & 20 \\
\hline Missouri & 24320 & 192073 & 13 \\
\hline Maryland & 13783 & 110278 & 12 \\
\hline Delaware & 587 & 18966 & 3 \\
\hline
\end{tabular}

Tabela composta com base no Censo de 1860. Disponível em:

$<$ https://www.census.gov/prod/www/decennial.html $>$.

Dessa forma, podemos compreender que o comprometimento dos estados secessionistas com a escravidão extrapola a consideração do papel central da economia estruturada na plantation e baseada no trabalho cativo, atingindo também todo o conjunto da sociedade. A defesa da escravidão e da expansão de seus laços entre não-proprietários de escravos estavam no centro do projeto de state-building confederado. A centralidade deste processo fica clara quando analisamos algumas das declarações de causas apresentadas pelos estados no momento de suas separações. Vejamos, por exemplo, o caso do Mississipi,

Our position is thoroughly identified with the institution of slavery-- the greatest material interest of the world. Its labor supplies the product which constitutes by far the largest and most important portions of commerce of the earth. These 
products are peculiar to the climate verging on the tropical regions, and by an imperious law of nature, none but the black race can bear exposure to the tropical sun. These products have become necessities of the world, and a blow at slavery is a blow at commerce and civilization. That blow has been long aimed at the institution, and was at the point of reaching its consummation. There was no choice left us but submission to the mandates of abolition, or a dissolution of the Union, whose principles had been subverted to work out our ruin. ${ }^{4}$

O trecho acima estampa o cabeçalho da declaração de motivos apresentada pelo Mississipi para sua separação, em relação a União, em 1861. A frase inicial é significativa para o argumento que busco tecer aqui, ela afirma que os interesses do Mississipi estão diretamente ligados à instituição da escravidão e a justifica a partir da noção de que o trabalho escravo se constituiria como um "bem maior" - a inspiração no argumento apresentado no ensaio "Slavery as a positive good", publicado pelo Senador John Calhoun, em 1837, é clara - para o comércio e o desenvolvimento da humanidade. Expostos à necessidade de escolher entre o fim da escravidão - e, por conseguinte, um impacto direto na ideologia da supremacia branca - e a separação em relação à União, os cidadãos do Mississipi escolheram pela última.

Os cidadãos do Mississipi, e de todos os outros Estados que haviam optado pela solução secessionista, dificilmente poderiam prever as dimensões do conflito em que estavam mergulhando, mas provavelmente acreditavam que, quaisquer que fossem as tempestades que os esperavam no futuro, elas nunca seriam tão traumáticas quanto a abolição da escravidão. Em seu discurso de posse, realizado meses antes da rendição do Fort Sumter, Jefferson Davis, agora presidente da Confederação, aludi à possibilidade de um conflito como algo a se considerar,

If we may not hope to avoid war, we may at least expect that posterity will acquit us of having needlessly engaged in it. Doubly justified by the absence of wrong on our part, and by wanton aggression on the part of others, there can be no cause to doubt that the courage and patriotism of the people

\footnotetext{
4"Nossa posição é completamente identificada com a instituição da escravidão - o maior interesse material do mundo. Seu trabalho fornece o produto que constitui, de longe, as maiores e mais importantes partes do comércio da terra. Estes produtos são peculiares ao clima das regiões tropicais, $e$, por uma lei imperiosa da natureza, ninguém além da raça negra pode suportar a exposição ao sol tropical. Esses produtos se tornaram necessidades do mundo e um golpe na escravidão é um golpe no comércio e na civilização. Esse golpe há muito tem sido destinado a esta instituição e chegou ao ponto de alcançar sua consumação. Não havia outra opção senão a submissão aos mandatos de abolição ou a dissolução da União, cujos princípios foram subvertidos para gerar nossa ruína." (Tradução nossa). A Declaration of the Immediate Causes which Induce and Justify the Secession of the State of Mississippi from the Federal Union. Disponível em: <http://avalon.law.yale.edu/19th_century/csa_missec.asp > . Acesso em: 24 fev. 2017.
} 
of the Confederate States will be found equal to any measures of defense which honor and security may require. ${ }^{5}$

A preocupação de Davis com a defesa do direito de secessão dos estados parece coerente com a ocasião, o chefe de um Estado justificava o direito de existência do próprio Estado. Contudo, algumas linhas abaixo de sua afirmação sobre a possibilidade de um conflito, Davis aponta como a condução de uma provável guerra pode ser destrutiva à economia sulista e procura vincular os interesses de produtores sulistas e consumidores no norte,

The cultivation of our fields has progressed as heretofore, and even should we be involved in war there would be no considerable diminution in the production of the staples which have constituted our exports and in which the commercial world has an interest scarcely less than our own. This common interest of the producer and consumer can only be interrupted by an exterior force which should obstruct its transmission to foreign markets--a course of conduct which would be as unjust toward us as it would be detrimental to manufacturing and commercial interests abroad. ${ }^{6}$

Apelando à razoabilidade, Davis procura vincular os interesses de produtores sulistas com os consumidores das commodities originadas nas plantations. A preocupação com o impacto de um conflito de grandes proporções na economia da Confederação transborda nas palavras do Presidente. Davis parecia considerar algum tipo de ação direta do Norte bloqueando o comércio sulista, mas em nenhum momento suas palavras parecem transparecer algum tipo de preocupação com o desafio de guiar à guerra um país que, considerando os dados do censo de 1860 , possuía quase quatro milhões de escravos. ${ }^{7}$

O impacto da própria guerra na escravidão não era um tema a ser considerado neste momento inicial do conflito, seria preciso que a situação das tropas sulistas começasse a se deteriorar para que o tema entrasse na pauta de discussão confederada. A princípio, a utilização de mão de obra negra para a realização de

\footnotetext{
5 "Se não podemos evitar a guerra, podemos pelo menos esperar que a posteridade nos absolva de ter se envolvido desnecessariamente nela. Duplamente justificados, pela ausência de erro da nossa parte e pela agressividade arbitrária da parte de outros, não pode haver motivo para duvidar de que a coragem $e$ o patriotismo do povo dos Estados Confederados serão iguais a quaisquer medidas de defesa que honra e segurança podem exigir." (tradução nossa). Inaugural Address. Alabama, Montgomery. 1861. Disponível em: https://jeffersondavis.rice.edu/Content.aspx?id=88. Acesso em: 24 fev. 2017.

6 "O cultivo de nossos campos progrediu até então, e mesmo se nos envolvermos na guerra, não haverá diminuição considerável na produção dos produtos básicos que constituem nossas exportações e nos quais o mundo comercial tem um interesse tão grande quanto nosso. Esse interesse comum do produtor e do consumidor só pode ser interrompido por uma força externa que deve obstruir sua transmissão para mercados estrangeiros - uma conduta que seria tão injusta para nós quanto prejudicial à produção e aos interesses comerciais no exterior." (Tradução nossa). Inaugural Address...

7 Censo de 1860. Disponível em: https://www.census.gov/history/www/through_the_decades/overview/ 1860.html Acesso em: 24 fev. 2017.
} 
obras de infraestrutura e logística militar foi compreendida como um valioso recuso para a ofensiva confederada. Ela seria fundamental para liberar o máximo de braços brancos possíveis para o combate, sendo necessário somente a manutenção de um pequeno contingente de brancos não combatentes na retaguarda para orientar os trabalhos e policiar as cidades. A escravidão era, portanto, o grande instrumento capaz de dar força à Confederação diante da grande disparidade demográfica. Podemos ver esta lógica de raciocínio no comunicado enviado pelo Major Samuel W. Melton, a James A. Seddon, então Secretário de Guerra da Confederação,

It is in our system of slave labor that our great strength consists; this it is which makes our $8,000,000$ productive of fighting material equal to the $20,000,000$ of the North; and time problem which must be worked out is so to adapt our peculiar system of labor as most effectually to relieve the fighting populations from the obligations of production and manufacture. A certain proportion of men must remain at home, it is true not to work, but to direct labor and maintain police. These purposes can be sufficiently met by the number exempt by reason of age and disease, it being better, I think, not to extend time ages which, over forty-five, will find many men incapacitated for service but who at the same time can answer all the purposes of economy. ${ }^{8}$

Também os periódicos sulistas reiteravam esse posicionamento, afirmando que a escravidão, na verdade, se constituiria como uma vantagem dos sulistas no conflito. Tom semelhante é seguido por um artigo do Chanceler e Senador Sul Carolineano William Harper, reproduzido na importante revista sulista "De Bow's Review" em julho de 1861,

It may be safely estimated that a population of twelve millions, one-third of whom are slaves, are equal in time of war to a population of twenty millions without slaves. Greece and Rome imbibed their proud and lofty natures and their indomitable spirit from that aristocratic position, which every citizen felt that he occupied when he looked down upon the less privileged slave class. They could turn out every citizen in

\footnotetext{
8 "É em nosso sistema de trabalho escravo que nossa grande força consiste; isto é o que torna nossos 8.000.000 combatentes iguais aos 20.000 .000 do Norte; e o problema que precisa ser resolvido é adaptar o nosso peculiar sistema de trabalho da maneira mais eficaz possível para aliviar as populações em conflito das obrigações de produção e manufatura. Uma certa proporção de homens deve permanecer em casa, é verdade, não para trabalhar, mas para dirigir o trabalho e manter a polícia. Esses propósitos podem ser suficientemente atendidos pelo número de isentos em razão da idade e da doença, sendo melhor, penso eu, não estender as idades, pois, aos quarenta e cinco anos, encontraremos muitos homens incapacitados para o serviço militar, mas que, ao mesmo tempo, podem responder a todos os propósitos da economia." (Tradução nossa). Samuel W. Melton to Hon. James A. Seddon, Secretary of War, Nov. 11, 1863. In: The War of the Rebellion: a Compilation of the Official Records of the Union and Confederate Armies. Disponivel em: <http://ebooks.library.cornell. edu/m/moawar/waro_fulltext.html>. Acesso em: 24 fev. 2017.
} 
a slave, with slaves to attend the camp and wait on the soldiery and yet leave slaves enough at home to carry on the ordinary and routine industry. History furnishes abundant proof that the institution of domestic slavery conduces to national strength; and the events of the day are about to confirm the lessons of history. ${ }^{9}$

O emprego dos cativos na realização de trabalhos de fortificação, construção de trincheiras e em toda logística demandada pela Guerra demonstram certa visão específica do trabalho na cultura sulista. Não somente o trabalho militar era visto como secundário, mas qualquer tipo de ofício manual carregava um certo estigma de inferioridade, marca de uma cultura profundamente aristocrática.

Ponto central nessa discussão sobre o papel dos escravos no conflito será a questão dos escravos que fugiam das linhas inimigas em direção aos acampamentos sob a justificativa de constituírem contrabando de guerra. A iniciativa de recusa do retorno de negros fugidos das linhas inimigas, tomada primariamente pelo General Benjamin Butler, ainda no acampamento em Fort Monroe, criou um precedente particularmente delicado e fez retornar as discussões sobre a questão da ação do Estado no regresso de escravos fugidos para seus respectivos donos. Mesmo dentro das linhas da União, a ação de Butler foi vista com reticência e seu potencial desagregador foi criticado, era uma medida bastante ousada, ainda mais em um momento em que a Confederação parecia se sair melhor nos embates militares iniciais. Parte dessa preocupação transparece na correspondência dos oficiais unionistas durante o conflito, como, por exemplo, nesta mensagem enviada pelo Major General Alexander McCook ao General Sherman, então comandante do Exército do Cumberland no front Oeste,

The subject of contraband negroes is one that is looked to by the citizens of Kentucky of vital importance. Ten have come into my camp within as many hours and from what they say there will be a general stampede of slaves from the other side of Green River. They have already become a source of annoyance to me and I have great reason to believe that this annoyance will increase the longer we stay. They state the reasons of their running away that their masters are rank secessionists in some cases are in the rebel army, and that

\footnotetext{
9 "Pode-se estimar com segurança que uma população de doze milhões, um terço dos quais são escravos, é igual em tempo de guerra a uma população de vinte milhões de pessoas sem escravos. Grécia e Roma desenvolveram suas orgulhosas e elevadas naturezas e seu espírito indomável justamente daquela posição aristocrática, que todo cidadão sentia que ocupava quando menosprezava a classe de escravos menos privilegiada. Eles poderiam transformar todo cidadão em um escravo, com escravos para assistir ao acampamento e esperar nos soldados e ainda assim deixar escravos suficientes em casa para continuar a indústria comum e rotineira. A história fornece provas abundantes de que a instituição da escravidão doméstica conduz à força nacional; os eventos do dia estão prestes a confirmar as lições da história." (Tradução nossa). De Bow's review. Vol.31. N.1. Julho de 1861. p.35. Disponível em: <http:/quod.lib.umich.edu/m/moajrnl/acg1336.1-31.001/38?node=acg1336.1-31.001 \%3A6\&view $=$ image\&size $=100>$. Acesso em: 24 fev. 2017.
} 
slaves of Union men are pressed into service to drive teams. I would respectfully suggest that if they be allowed to remain here our cause in Kentucky may be injured. I have no faith in Kentucky's loyalty therefore have no great desire to protect her pet institution slavery.

I have put the negroes to work. They will be handy with teams and generally useful. I consider the subject embarrassing and must defer to your better judgment. ${ }^{10}$

As desconfianças de McCook com relação à fidelidade do Kentucky, Border State escravocrata, também eram partilhadas pela maioria dos políticos republicanos à época. A relutância de Lincoln na assinatura do Confiscation Act de 1861 e, posteriormente, na sua aplicação efetiva, mostram claramente como este assunto era bastante controverso, mesmo entre os Unionistas. A política só iria se tornar claramente viável no ano seguinte, quando seria confirmada no Act Prohibiting the Return of Slaves, mas, nesse ponto, a situação do conflito já era outra e a posição de Lincoln era muito mais confortável, tanto no quesito militar, quanto na garantia da fidelidade dos Border States.

Até então, constatamos que a questão da fuga de escravos é um ponto fundamental para a compreensão da relação entre a instituição da escravidão e o esforço de guerra confederado, todavia, é preciso que a abordemos a partir de uma outra perspectiva. A questão central que ocupa o debate historiográfico atual sobre esta temática diz respeito à agência dos escravos na condução da guerra e impacto dessas fugas no esforço de guerra da confederação. Stephanie McCurry, por exemplo, argumenta que, por conta das exigências geradas pelo conflito, o Estado Confederado teve, durante seu processo de state-building, que considerar determinados grupos sociais que estavam historicamente excluídos do projeto inicial. ${ }^{11} \mathrm{Em}$ seu ponto de vista, a fuga destes escravos acabou criando um novo "front interno" de combate, que acabou enfraquecendo e minando as estruturas sulistas a partir de dentro.

Ainda que concorde com a ideia de que as fugas de escravos e os confiscos acabaram por demonstrar uma fraqueza intrínseca da manutenção de uma guerra na qual a escravidão acaba por tomar parte central na luta, discordo de McCurry na

10 "O tema dos negros contrabandeados é considerado pelos cidadãos de Kentucky de vital importância. Dez pessoas entraram em meu acampamento nas últimas horas e, pelo que dizem, haverá uma debandada generalizada de escravos do outro lado do Rio Verde. Eles já se tornaram uma fonte de aborrecimento para mim e tenho grandes razões para acreditar que esse aborrecimento aumentará quanto mais tempo ficarmos aqui. Eles afirmam que as razões de suas fugas são a adesão de seus senhores à causa secessionistas e que, em alguns casos, estes senhores estão no exército rebelde, mesmo escravos de homens fies à União são pressionados a realizar trabalhos. Eu, respeitosamente, sugiro que caso eles permaneçam aqui, nossa causa no Kentucky pode ser ferida. Eu não tenho fé na lealdade do Kentucky e, igualmente, não tenho grande desejo de proteger a instituição de estimação deles, a escravidão. Eu coloquei os negros para trabalhar. Eles serão úteis em equipes. Considero o assunto embaraçoso e resolvi submetê-lo ao seu melhor julgamento." (Tradução nossa). Alexander McCook to General W. T. Sherman, 5 de Novembro de 1861. Camp. In: The War of the Rebellion: a Compilation of the Official Records of the Union and Confederate Armies. Disponivel em: <http://ebooks.library.cornell.edu/m/moawar/waro_fulltext.html>. Acesso em: 24 fev. 2017.

11 McCURRY, Stephanie. Confederate Reckoning: Power and politics in the civil war South. Massachusetts: Harvard University Press, 2010. 
medida em que creio que sua análise exagera no papel da agência escrava e aponta o movimento de fuga quase como uma atitude articulada conscientemente para a desestruturação das bases de apoio do Estado Confederado. McCurry também assume o conceito de formação do Estado de maneira axiomática, de forma que sua inserção no conjunto do argumento é, algumas vezes, complexa e nebulosa.

De toda forma, nos parece legítimo afirmar que a questão das fugas, gerada pela política de apreensão de ex-escravos por parte dos exércitos do Norte, exerceu influência negativa na condução do esforço de guerra sulista. Este processo se deu não por uma natural tendência dos regimes escravocratas durante a guerra, mas, principalmente, pela centralidade que a temática da manutenção, ou do fim da escravidão, tomou em todo o conflito, que acabou por identificar os lados beligerantes com ambos espectros deste processo. Fosse uma guerra entre duas nações escravocratas, ou uma guerra em que a União não demonstrasse grande interesse na imposição do trabalho livre por toda a nação, essa temática não adquirira a centralidade que teve.

A necessidade de cada vez mais braços por parte do Estado confederado provocará tensões na estrutura federativa confederada. As constantes requisições por contingente - tanto de homens brancos para as fileiras de combate, quanto de escravos para a execução das obras de logística - gerarão crescente oposição entres as autoridades locais, especialmente os governadores de estado, e o Governo central. Essa oposição é capaz de nos demonstrar um dos mais curiosos paradoxos gerados pela inserção da Confederação no conflito, o Estado que se construiu sobre a retórica do direito dos Estados, durante seu próprio processo de state-building, percebe a necessidade de agir de maneira centralizadora na busca por recursos para a condução do conflito. Richard Bensel, por exemplo, afirma que a mobilização de guerra na confederação deu origem a um estado profundamente centralizado e poderoso, mas ressalta que as dificuldades estruturais da confederação tornavam esse processo muito difícil de ser realizado,

Although other features of the Confederate state similarly demonstrate the comprehensive mobilization of the southern nation, the synergistic combination of conscription and impressment policies constituted the foundation of the Confederate war effort. Although some aspects of these and other policies were spelled out in law, most authority conferred upon the central state allowed executive or bureaucratic discretion. And, although this discretion could theoretically have been used to enhance the planning capacity and centralizing tendencies of the state, in practice both technological deficiency (primarily in telegraphic communication but later extending to transportation) and chronic shortages in materiel and manpower forced a much 
Dessa forma, pode-se afirmar que o Estado Confederado se caracteriza por uma condição de centralização incompleta, ou seja, ainda que possuísse um grau significativo de concentração da autoridade legal em torno do Governo central, as limitações na capacidade administrativa acabaram por enfraquecer a eficiência destas ações diante das autoridades locais. As limitações se dão, em parte pela falta de recursos para o desenvolvimento de uma logística de apoio e, em maior grau, pela resistência concreta de alguns chefes do poder local - especialmente os governadores - em colaborar com as exigências impostas pelo governo de Richmond.

A questão da escravidão voltaria a tomar o protagonismo no discurso sobre o esforço de guerra confederado alguns meses antes da derrota final. Por volta de novembro de 1864, os debates sobre a necessidade da utilização de negros nas fileiras do exército confederado já colocavam em oposição os sulistas. Ao lado daqueles que apoiavam a solução do alistamento, seguido da emancipação destes soldados negros, estavam dois nomes de peso, o Presidente Jefferson Davis e o General Robert E. Lee. A questão só seria resolvida bem mais tarde, em março de 1865 - apenas um mês antes de Appomattox -, quando o Congresso Confederado votou a favor de uma lei autorizando o recrutamento de soldados negros.

Ainda que de pouco significado no conjunto do esforço militar, afinal, a decisão veio tarde demais para gerar qualquer impacto positivo na capacidade bélica confederada, a aprovação da utilização de escravos como soldados nos serve como importante elemento para a análise das relações conflitantes entre a condução da Guerra e a instituição da escravidão. Mais do que os discursos de apoio à decisão, sempre pautados no reforço da necessidade de mais homens e no potencial que poderia ser gerado com a liberação destes homens sob a condição do recrutamento, são as falas contrárias a proposta que apontam o quão incongruente parecia ser, ao menos aos olhos de alguns, essa decisão.

Robert M. T. Hunter, então presidente do Senado Confederado, faz ecoar uma dúvida que, provavelmente, ocupava a cabeça de muitos senhores de escravos diante da proposta, "What did we go to war for, if not to protect our property?". ${ }^{13}$ Indo além, Henry S. Foote, representante do Tennessee no congresso confederado deixará claro o paradoxo que reforça o argumento que apresentei algumas páginas acima. Em

12 "Embora outras características do Estado Confederado demonstrem de forma semelhante a mobilização abrangente da nação do Sul, a combinação sinérgica das políticas de recrutamento e de conscrição constituiu a base do esforço de guerra da Confederação. Não obstante alguns aspectos dessas e outras políticas tenham sido explicitados em lei, a maior parte da autoridade conferida ao Estado central permitiu a discrição executiva ou burocrática. E, embora essa discrição pudesse teoricamente ter sido usada para melhorar a capacidade de planejamento e centralizar as tendências do Estado, na prática, tanto a deficiência tecnológica (principalmente na comunicação telegráfica, mas depois se estendendo também ao transporte), quanto a escassez crônica de material e mão de obra, forçaram a um aparato de controle muito mais descentralizado sobre a Confederação." (Tradução nossa). BENSEL, Richard Franklin. Yankee Leviathan: The Origins of Central State Authority in America. New York: Cambridge University Press, 1990, p. 181.

13 "Por que nós iríamos para a Guerra se não fosse para proteger nossas propriedades?" (Tradução Nossa). FOOTE, Shelby. The Civil War: A narrative. New York: Random House, 1974, p. 766. 
sessão do Congresso que deliberava sobre a questão da utilização de escravos como soldados confederados, ele afirma "If this governement is to destroy slavery, why fight for it?". ${ }^{14}$

As colocações de Hunter e Foote nos situam diante do paradoxo central que se encerra na relação entre Escravidão e esforço de Guerra. À medida que o conflito foi se agudizando, a manutenção da escravidão $e$ as exigências do conflito foram se colocando em rota de colisão. No momento mais extremo desse processo, quando tudo apontava para a derrota da Confederação, as lideranças sulistas foram colocadas diante da impossibilidade da manutenção do regime escravocrata, ao menos no modelo pré-guerra. A possível libertação de alguns escravos para o serviço militar criava um precedente perigoso, capaz de solapar uma instituição que estava na origem constitutiva do próprio Estado. Quando a defesa da manutenção da propriedade escrava, agente motivador original da secessão, acaba deixando de identificar-se com o Estado Confederado, suas estruturas internas passam a ruir. A Confederação havia sido, enfim, atingida por um golpe da mesma "double-Edged Sword" que empunhou desde as primeiras escaramuças no Fort Sumter.

\section{A noção de Estado Propositivo como instrumento para explicar a centralização da autoridade e capacidade administrativa no esforço de guerra da União}

É importante, a princípio, definirmos alguns dos conceitos que nos servirão de base para o argumento que pretendemos desenvolver aqui. Ao longo das próximas páginas, produziremos uma pequena análise do design estrutural do Estado nortista durante a Guerra Civil. Para tanto, utilizaremos como base teórica as noções de centralização da autoridade - explorada, de certo modo, na resposta anterior sobre a confederação - e capacidade administrativa. ${ }^{15}$ Entendemos por centralização da autoridade o conjunto de políticas que busca concentrar diferentes estágios de tomadas de decisão em um pequeno número de instituições ou mesmo uma única instância do Estado. Por capacidade administrativa, compreendemos o grau de desenvolvimento da sua burocracia e a cobertura das diversas estruturas do Estado sobre um determinado território reclamado.

Como pode ser inferido desta definição prévia, uma ampliação na centralização da autoridade - movimento costumeiro em períodos de conflito militar - conduz a uma maior agilidade na tomada de decisões e uma maior capacidade do Estado Central em gerir e ditar as práticas de seus subordinados. Da mesma forma, uma ampliação na capacidade administrativa pode ser capaz de ampliar o potencial extrativo deste

\footnotetext{
14 "Se esse governo visa destruir a escravidão, por que lutar por ela?" (Tradução nossa). Proceedings of the Second Confederate Congress. Southern Historical Society Papers, vol. 51, p. 276. <Disponível em: https://memory.loc.gov/ammem/amlaw/lwcc.html>. Acesso em: 24 fev. 2017.

${ }^{15}$ As bases de consulta para a compreensão destes conceitos foram: EVANS, Peter, RUESCHEMEYER, Dietrich, SKOCPOL, Theda. On the road toward a more adequate understanding of the state. In: Bringing the State Back In. Cambridge: Cambridge University Press, 1985, p. 350-353; BENSEL, Richard Franklin. Yankee Leviathan: The Origins of Central State Authority in America. New York: Cambridge University Press, 1990, p. 106.
} 
Estado, bem como reprimir quaisquer movimentos centrífugos - ponto primordial no cenário histórico que iremos analisar.

Outro ponto que deve ser ponderado em qualquer análise sobre o impacto do esforço de guerra na estrutura de cada Estado é a consideração sobre as diferentes relações entre a capacidade organizacional $e$ a base econômica sobre a qual ele se estrutura. As demandas do esforço de Guerra, na maioria das vezes, esgotam a capacidade extrativa do Estado, obrigando-o a procurar novas formas de extração, servindo, especialmente, como bom momento para a reconsideração de sistemas de taxação e, por conseguinte, produzindo toda uma remodelagem do aparato extrativo. O que a experiência da Guerra Civil - ao menos pelos olhos do Norte - nos mostra é uma estrutura de mobilização e financiamento diretamente orientada às exigências do mercado, substanciada em contratos voluntários entre Estado e fornecedores $e$ baseada em um sistema de recrutamento que se organizava sobre cotas estatais $e$ recompensas.

Assim sendo, ao menos de um ponto de vista econômico, o esforço de guerra da união foi apoiado primariamente nos mercados e na produção industrial voluntária, com pouca interferência Estatal direta e, por conseguinte, pouca ampliação na centralização da autoridade. Pode-se dizer, portanto, que o esforço de guerra da União não atingiu negativamente os setores industriais não militares e a agricultura. $\mathrm{O}$ Estado procurou, conscientemente, não intervir nesses setores e, mesmo nos pontos onde o esforço de guerra poderia causar algum dano - refiro-me aqui especialmente à repercussão dos recrutamentos sobre a disponibilidade de mão de obra -, seu impacto foi tímido.

Do ponto de vista da capacidade econômica do Norte, os inimigos sulistas não apresentaram desafio bastante para levar a capacidade produtiva nortista a níveis de exaustão. Dessa forma, ao menos no que diz respeito ao potencial econômico e à capacidade de mobilização, o esforço de guerra capitalista do Norte se mostrou mais que suficiente para concluir favoravelmente o conflito sem grandes impactos na lógica do mercado. Pelo contrário, a Guerra foi um instrumento interessante para a ampliação da lógica industrial que subjazia algumas das bases principais da ideologia do trabalho livre defendida pelo projeto republicano.

Talvez o único ponto em que a ação do Estado nortista tenha se feito mais presente foi no Sistema Financeiro nacional. O esforço de guerra ajudou a consolidar uma classe de financistas americanos capazes de fomentar recursos cada vez mais independentes dos investimentos europeus. Esse tipo de ação tem seu símbolo mais significativo na ascensão dos dólares como padrão de moeda e, principalmente, na ampliação considerável do papel do Tesouro como mediador entre o Estado e o mercado.

Ainda que, do ponto de vista econômico, o esforço de guerra não tenha atingido diretamente a estrutura do Estado no Norte, ou mesmo realizado grandes transformações centralizadoras no governo de Washington, a dimensão sem precedentes do conflito exigiu, especialmente a partir de 1862-63, que políticas também inéditas fossem colocadas em andamento para a realização das exigências demandadas pelo esforço militar. O Enrollment Act, de 1863, talvez seja o ápice desse processo de centralização do Estado exigido pelo esforço de guerra. A lei instituía um sistema de sorteios e previa a possibilidade da apresentação de substitutos ou do 
pagamento de uma indenização para a liberação das obrigações militares - a instituição de uma indenização visou evitar o crescimento de um mercado de substitutos supervalorizado.

Até este momento, o recrutamento havia se baseado principalmente no voluntariado e no cumprimento de cotas específicas por Estados, se tratava de um modelo de condução do esforço de guerra muito mais difuso e pautado na habilidade dos oficiais locais na preparação das listas e no cumprimento das quotas. ${ }^{16} \mathrm{O}$ sistema de cotas baseava-se diretamente na capacidade das autoridades locais de preencherem suas metas. Era, portanto, um arranjo profundamente construído em torno da lógica estrutural federativa, atribuindo responsabilidade às diferentes autoridades locais na condução do esforço de guerra. Há, nessa decisão, certa preocupação com a condução da guerra do ponto de vista do Estado Central. Como a questão do direito dos Estados havia assumido papel central nos debates anteriores à secessão - $e$, principalmente, tendo em vista o cuidado com que Lincoln parecia agir com relação aos Border States escravocratas que se aliavam à União -, a condução de qualquer tipo de política central de conscrição deveria ser levada adiante com cuidado.

Dessa forma, o Enrollment Act e a instituição do modelo de drafts modificam um pouco o cenário do design do estado no Norte, não somente aumentando sua ação centralizadora, mas expandido sua capacidade administrativa através de toda uma burocracia incumbida da gerência do sistema de sorteios e das listas de nomes por região. Talvez o melhor exemplo desse processo de expansão da estrutura da burocracia estatal seja a importância adquirida pelos Provost Marshal nesse momento.

O Enrollment Act, em conjunto com outras práticas de centralização governamental, como o Financial Bill, o Bank Act - que acabaria por dar forma ao Sistema Bancário americano, ao instituir o Office of the Comptroller of the Currency, subordinado ao Tesouro Nacional -, além, é claro, da suspensão do direito de Habeas Corpus, constituem-se como elementos significativos do esforço de ampliação da centralização da autoridade do Estado. Pode-se argumentar que, mais que um processo natural de centralização do controle do Estado durante um período de guerra, tratava-se da utilização consciente da máquina estatal para o controle das oposições ao conflito e das forças centrífugas ainda existentes no Norte. Esse processo foi percebido e interpretado de diferentes formas pelos contemporâneos. A revista Harper's Weekly, simpática ao projeto republicano, discute a questão nos seguintes termos,

It is quite evident that in the face of such a state of things, and when the nation is engaged in a death-grapple of which the issue is very doubtful, the slow and cautious remedies which the law provides for the redress of wrongs in time of peace would be out of place. [...] When we undertook the war we

\footnotetext{
${ }^{16}$ Como forma de incentivo ao alistamento voluntário foram oferecidas algumas recompensas por parte dos Estados. O processo de pagamento de recompensas gerou todo um sistema de corrupção, criando mesmo uma casta de caçadores destas recompensas. Este processo é estudado por Eugene Murdock em: MURDOCK, Eugene C. New York's Civil War Bounty Brokers. Journal of American History, vol. 13, 1966, p. 259-78.
} 
tacitly agreed to accept it with all its evils. Prominent among these are a depreciated currency, a temporary deprivation of personal liberty, and a liability to be taken from one's business to carry a musket in the army. These are grave inconveniences. But they are temporary and bearable; whereas the evils which would result from the disruption of the Union are lasting and intolerable. We may suffer, but our children will benefit by our suffering. Whereas if this country is severed in twain the future which lies before us is plainly depicted in the history of Mexico and Central America: incessant wars, constant subdivisions, a cessation of honest industry and agriculture, a decay of trade, a disappearance of wealth and civilization, and in their stead chronic strife, rapine, bloodshed, and anarchy. To avoid these things we can well afford for a few years to have a strong Government. ${ }^{17}$

Essa postura compreensiva que enxergava o fortalecimento do poder central como um exercício de sacrifício diante de uma causa maior não era compartilhada por todos os atores envoltos no esforço de guerra. As respostas dadas por alguns governadores do Upper South diante ainda das primeiras chamadas por tropas, deixam claro o clima particular de tensão naqueles estados e a maneira com a qual a Estrutura federativa atingia diretamente a capacidade de mobilização e o esforço de guerra - ainda que esse processo tenha sido mitigado com o desenvolvimento do conflito. O Kentucky, por exemplo, afirma, em resposta à solicitação por tropas de Lincoln, que: "Will not furnish no troops for the wicked purpose of subduing her sister Southern States" ${ }^{18} \mathrm{O}$ tom da afirmativa é compartilhado pelo Tennessee, que assegura: "We will not furnish a single man for the purpose of coercion, but Fifty Thousand if necessary for the defense of our rights and those of our Southern Brothers". ${ }^{19}$

\footnotetext{
17 "É bastante evidente que, diante de tal estado de coisas, quando a nação está engajada em uma situação de vida ou morte muito duvidosa, os remédios lentos e cautelosos que a lei provê para a reparação de injustiças no tempo de paz estão fora de lugar [...] Quando assumimos a guerra, concordamos tacitamente em aceitá-la com todos os seus males. Destacam-se, entre estes, a depreciação da moeda, a privação temporária de liberdade pessoal e possibilidade de ser retirado de seus afazeres para ir empunhar um mosquete no exército. Esses são inconvenientes graves, mas eles são temporários e suportáveis; considerando que os males que resultariam da ruptura da União são duradouros e intoleráveis. Podemos sofrer, mas nossos filhos serão beneficiados pelo nosso sofrimento. Ao passo que, se este país for dividido em dois, o futuro que está diante de nós é aquele claramente descrito na história do México e da América Central: guerras incessantes, constantes subdivisões, cessação da indústria e agricultura, decadência do comércio, desaparecimento da riqueza e da civilização e, em seu lugar, conflitos crônicos, rapina, derramamento de sangue e anarquia. Para evitar essas coisas, devemos nos dar ao luxo de ter um governo forte por alguns anos." (Tradução nossa). Harper's Weekly. 14 de março de 1863, p. 2.

18 "Não forneceremos tropa alguma para o ímpio propósito de subjugar nossos estados irmãos do Sul." (Tradução nossa).

19 "Não forneceremos nem mesmo um só homem com o objetivo de coerção, mas cinquenta mil, se necessário, para a defesa de nossos direitos e daqueles dos nossos irmãos do Sul”. (Tradução nossa).
} 
Especialmente nesses estados, que acabariam mantendo-se fiéis à União, a capacidade de negociação e controle da estrutura federativa foi fundamental para a manutenção do esforço de guerra. O que se pode assegurar é que, de fato, há um processo mútuo de tentativa de ampliação da centralização do Estado e, uma vez que o Estado nacional tinha um conjunto estrutural administrativo muito mais denso no Norte que no Sul, uma utilização da máquina administrativa com vistas à consolidação do projeto republicano.

\section{Conclusão: Os impactos dos esforços de guerra $e$ as duas estruturas estatais diferenciadas}

Envoltos nas necessidades geradas pela guerra, tanto União quanto Confederação desenvolveram políticas que buscavam centralizar grupos de decisão em torno de algumas instâncias do governo central. Alguns dos pontos em que as iniciativas centralizadoras de ambos governos beligerantes se aproximam foram, por exemplo, a adoção de um regime de segredo para algumas sessões legislativas, a criação de legislações que davam ao presidente a premissa de assinalar oficiais comissionados sem a necessidade de anuência dos governadores de estados - entre estes os Provost Mashalls, citados anteriormente -, além de ações mais diretas contra oposicionistas, como a exclusão de representantes diretamente eleitos nas assembleias locais.

Quase todas estas ações guardavam algum paralelo com políticas também desenvolvidas no estado Sulista. Contudo, o processo de concentração do Estado no Norte adquiriu algumas cores bastante peculiares, como por exemplo, a criação de legislações autorizando a utilização de milícias dos Border States fora de seus estados de origem, a criação do Freedmen's Bureau, a nacionalização da moeda e, obviamente, todo o desenvolvimento de uma política de reconstrução voltada para a reforma das instituições do Sul após a vitória militar.

A constatação dessas ações centralizadoras por parte da União não nos dá base suficiente para assegurar que este estado passou por um processo de centralização maior ou menor do que aquele assistido no Sul durante a Confederação. Ainda que os governos de Washington e Richmond tenham agido conscientemente em busca de uma centralização do estados e controle das ações mais relevantes na sua estrutura organizacional, a própria situação sui generis de conflito - no caso Confederado, o Estado passará toda a sua existência em beligerância -, em que os dois governos se encontravam, fazia com que essas medidas se tornassem uma demanda estrutural. Todavia, acredito que a melhor forma de tentar compreender estas diferentes tendências de centralização, e suas interseções, é a observação das diferenças de razão ontológica sob as quais se assentava a existência dos dois Estados.

A razão ontológica da Confederação é necessariamente defensiva, ou seja, a sua própria existência e, por conseguinte, os argumentos que ela poderia mobilizar para justificar uma ação mais direta sobre as estruturas locais e a vida de seus cidadãos, se baseava necessariamente na manutenção de uma instituição, a escravidão, e na forma com que o desenvolvimento da Guerra necessitava de medidas mais urgentes por parte do governo. O que isso nos mostra, conforme quis apresentar na primeira questão deste trabalho, é que o processo de estruturação e desenvolvimento do Estado confederado estava diretamente ligado à sua capacidade de servir de esteio 
para a manutenção do modelo escravocrata. Na medida em que o Estado se mostrava mais fraco na defesa desta instituição, principalmente pelos reveses militares, os argumentos que substanciavam sua centralização foram esfacelando-se.

$\mathrm{O}$ caso da União é diferente, o governo de Washington baseava-se em uma razão ontológica diretamente propositiva, ou seja, sua existência se dava pela execução de um projeto de nação bastante claro, que servia de base e justificativa para a centralização Estatal. O papel da ideologia do trabalho livre republicana, no conjunto das ações centralizadoras engendradas pelo estado Unionista, não pode ser desvalorizado. A criação de um modelo de reconstrução para o Sul, após o fim do conflito, e a instituição de um Freedmen's Bureau está diretamente coadunada com essa dimensão propositiva do Estado.

Também aqui havia um elemento diverso, a existência de uma oposição interna, especialmente alguns políticos Democratas do Norte e os antagonistas da guerra, em geral, além de elementos hesitantes dentro do conjunto dos Estados que compunham a União, especialmente nos Border States. Aqui, a centralização do Estado assume também o papel coercitivo, ou seja, procura retirar a capacidade de manobra de alguns elementos contrários ao conflito dentro da lógica do estado nortista.

Comparado ao esforço centralizador Confederado, o Estado Unionista parece ter conseguido maior grau de capacidade de execução de políticas, resultado direto da sua natureza propositiva. Contudo, essa capacidade não repercutia, em um domínio onisciente, sobre todos os territórios subordinados. A União era muito mais forte na sua capacidade de construção e imposição de políticas ao resto do país, do que no controle das atividades internas dos Estados. Ainda que a centralização e a organização das atividades militares confederada tenham ficado bastante à frente da União, o Estado Nortista, pela sua capacidade econômica, superioridade demográfica e por sua natureza propositiva, foi capaz de impor um projeto claro de nação que transformaria o país daquele momento em diante.

\section{$\operatorname{son} 2$}




\section{RESUMO}

A Guerra Civil Americana foi o maior conflito militar da história das Américas. De dimensões até então inéditas, a guerra não só consumiu muito mais vidas do que se estimava, como também se tornou um rasgo fundamental na construção da nação norte-americana, definindo suas bases valorativas e seu modelo produtivo. Partindo desse princípio, buscaremos explorar neste artigo os diferentes desafios estratégicos e estruturais que se impuseram no esforço de guerra, tanto da Confederação quanto da União. Em relação à Confederação, examinaremos de que forma se relacionaram a defesa da escravidão $e$ as necessidades demandadas pelo esforço de Guerra. Já no que diz respeito à União, nossa investigação analisará de que forma a mobilização militar e a necessidade de supressão de forças centrípetas existentes dentro do próprio conjunto dos Estados não rebelados se chocaram com a busca de centralização da autoridade estatal em um momento de conflito civil. Em um último movimento, buscaremos contrapor essas duas experiências de mobilização militar para responder uma questão fundamental: quais foram as consequências estruturais da guerra para o Estado americano e de que forma estas condições ajudam a explicar o resultado do conflito.

Palavras Chave: Guerra Civil Americana; Formação do Estado; Mobilização.

\section{ABSTRACT}

The American Civil War was the largest military conflict in American history. From hitherto never seen dimensions, the war not only consumed much more lives than was estimated, but also became a fundamental feature in the construction of the American nation, defining its bases and productive models. Based on this principle, we will seek to explore in this article the different strategic and structural challenges imposed by the war effort, both in the Confederation and in the Union. In relation to the Confederation, we will examine how the defense of slavery and the needs demanded by the War effort were related. As far as the Union is concerned, our investigation will examine how the military mobilization and the need to suppress centripetal forces within the group of non-rebel states themselves have clashed with the search for centralization of state authority at a time of civil conflict. In a last movement, we will try to compare these two experiences of military mobilization and answer a fundamental question: what were the structural consequences of the war for the American state and how do these conditions help explain the outcome of the conflict.

Keywords: American Civil War; State formation; Mobilization.

Artigo recebido em 20 jun. 2017.

Aprovado em 14 jun. 2018. 